\title{
Making Evaluation More Responsive to Policy Needs: The Case of the Labour Market Development Agreements
}

\section{Yves Gingras, Tony Haddad, Andy Handouyahia, Georges Awad, and Stéphanie Roberge Employment and Social Development Canada}

\begin{abstract}
This note describes how Employment and Social Development Canada evaluation staff transformed the Labour Market Development Agreement (LMDA) evaluation process to make it more timely, cost-effective, and relevant for policy development. The note provides background on the LMDAs and discusses key drivers for changing the evaluation approach. In particular, it describes the benefits of using small targeted studies, rich administrative panel data, and building in-house evaluation capacity. It concludes with some lessons learned for the evaluation practice.
\end{abstract}

Keywords: administrative data, capacity building, evaluation approach

Résumé : Cette note décrit comment l'équipe de l'évaluation de programmes à Emploi et Développement social Canada a transformé l'évaluation des ententes sur le développement du marché du travail (EDMT) afin d'accroître sa pertinence pour le développement des politiques, réduire le temps nécessaire pour conduire l'évaluation et rendre le processus plus efficient. Cette note présente les EDMT et décrit les facteurs qui ont conduit à changer l'approche d'évaluation. De façon spécifique, elle présente les avantages de mener de petites études d'évaluation ciblées, de miser sur l'analyse de données administratives longitudinales et de développer une capacité d’évaluation interne. Elle conclue avec des leçons apprises pour la pratique de l’évaluation.

Mots clés : données administratives, amélioration de la capacité, approche d'évaluation

\section{INTRODUCTION}

Departments such as Employment and Social Development Canada (ESDC) increasingly expect evaluators to produce targeted and timely information to support ongoing policy work. The need to produce more timely and relevant evaluation pushes evaluators to rethink how they do evaluation. Conducting a rigorous

Corresponding author: Yves Gingras, Director General, Evaluation Directorate, Employment and Social Development Canada, 140 Promenade du Portage, Phase IV, Gatineau (Quebec), K1A 0J9, <yves.gingras@hrsdc-rhdcc.gc.ca> 
evaluation usually entails several methodological, quality control, and approval steps that can make the process very lengthy. However, as reported by Bourgeois and Lahey (2014), in the recent past the lack of timeliness of evaluation in ESDC was often a barrier to its use.

The pressure to innovate also became greater with the introduction of the 2009 Policy on Evaluation (Government of Canada, Treasury Board Secretariat, 2009) that required an evaluation of all program spending every five years. On one hand, the evaluation function had to develop more capacity to meet policy requirements. On the other hand, expanding the capacity was limited by budget constraints (Bourgeois, Toews, Whynot, \& Lamarche, 2013).

This particular context motivated evaluators at ESDC to rethink how they evaluated $12 \mathrm{federal} /$ provincial/territorial bilateral administrative agreements. The purpose of this practice note is to describe how the bilateral approach for evaluating those 12 agreements was streamlined into one continuous evaluation process. With this new approach, evaluations on different aspects of the agreements are conducted and released simultaneously for all provinces/territories and for Canada periodically. As well, the evaluation builds on the fact that rich administrative data are available to estimate outcomes and impacts and to conduct analyses in-house.

The note first describes the LMDAs and then highlights the drivers for changing the evaluation approach. It next explains the key features of the new approach and its observed benefits. It concludes by discussing lessons learned from this experience.

\section{THE LABOUR MARKET DEVELOPMENT AGREEMENTS (LMDAS)}

Introduced in 1996 under Part II of the Employment Insurance Act, the LMDAs are agreements between the Government of Canada and each of the 13 provinces and territories. They include the transfer of $\$ 1.95$ billion annually from the federal government for the delivery of employment programs and services that help mostly Employment Insurance-eligible unemployed individuals find and maintain employment. ${ }^{1}$

Since 2010, provinces and territories have had full responsibility over the design and delivery of LMDA-funded programs and services as long as they correspond to categories defined in the Employment Insurance Act. The categories include, for example, financial assistance for training. These categories are similar to the main type of active labour market programs delivered in other countries (Gunderson, 2003) and to those used in other federally funded employment programs.

\section{DRIVERS FOR RETHINKING THE EVALUATION APPROACH}

The LMDAs require a first summative evaluation in the third year of the agreement's implementation ${ }^{2}$ and subsequent evaluations of the impact and effectiveness 
of the programs every three to five years. Each province and territory has the choice of evaluating their LMDA on their own or jointly with the Government of Canada. Every province and territory except Quebec opted for a joint evaluation.

Twelve bilateral formative evaluations were conducted between 1998 and 2012 and were followed by 12 bilateral summative evaluations conducted between 2002 and 2012. Each summative evaluation took two to three years to complete. Because the evaluation team had the capacity to conduct two to three evaluations at the same time, it was not possible to comply with the LMDA evaluation clause and the Treasury Board's Policy on Evaluation (2009). The process was lengthy and costly because each evaluation was undertaken by external contractors and relied on large surveys to collect information on program outcomes and impacts. Approximately \$10 million was spent in external contracts alone.

When planning for the second cycle in 2011-2012, expanding the evaluation capacity to carry more bilateral evaluations at the same time was not an option given the budget constraints. The only realistic option was to rethink the evaluation approach to increase efficiency but also to make the evaluations more useful.

Academics and stakeholders (e.g., industry representatives) raised concerns with the accountability around the LMDAs and the fact that no national level assessment was available (Canada, 2015). Federal and provincial/territorial representatives also thought that the findings from the first round of summative evaluations were of limited use, partly because of the lack of timeliness and the limited evidence they generated about the program effectiveness in some jurisdictions. ESDC had to rely on surveys of participants and nonparticipants to estimate impacts. These surveys often resulted in small sample size that made quantitative analyses of impacts difficult. As well, to minimize recall errors, the survey followed individuals only over the short term after participation, although a fair assessment of employment program impacts requires a longer observation period. As shown in the literature, impacts of employment programs are often more positive in the medium- to long-term compared to the short-term (Card, Kluve, \& Weber, 2015). Finally, it was difficult for federal officials to get an overall understanding of LMDA effectiveness as it was challenging to roll up impacts from 12 different evaluations undertaken over 10 years.

\section{THE NEW APPROACH}

The second round of evaluations took place between 2012 and 2016 using a new approach developed in consultation with provinces/territories and ESDC program managers and policy makers. Key features include

\section{Breaking the evaluation into small annual studies undertaken at the national and provincial/territorial levels simultaneously}

Two to three studies were conducted annually over a span of five years. Findings were generated for Canada overall and for each province/territory separately. One annual study measured program incremental impacts on key labour market 
indicators (e.g., earnings) over the short- and medium-term after participation and for various groups of participants (e.g., youth, older workers) or time periods (i.e., short- and medium-term after participation).

One or two additional studies were conducted using targeted questions about program design, delivery, relevance, effectiveness, and efficiency, with a goal of supplementing what was already known about the LMDAs. For example, some studies examined the design and delivery of specific programs (e.g., skill training) to identify best practices and understand how they are targeted. Another study examined how the timing of participation in Employment Assistance Services affects participants' labour market impacts. Evaluators also completed the firstever cost-benefit analysis of LMDA programs based on six years of postprogram data. Using a similar framework as in Bloom et al. (1997), Heckman, Lalonde, and Smith (1999), and Heckman, Moon, Pinto, Savelyev, and Yavitz (2010), the analysis estimated the extent to which benefits from the program exceeded the costs six years after the end of participation.

\section{Multilateral and bilateral governance process}

A two-level governance structure was put in place to oversee the evaluation process. An Evaluation Steering Committee consisting of representatives of ESDC and the 12 participating provinces/territories was mandated to decide on the evaluation work plan as well as to approve the methodologies and the national reports. Joint Evaluation Committees including representatives of ESDC and officials from each participating province and territory were also set up to discuss issues specific to each jurisdiction.

\section{Ongoing consultation of evaluation partners on the scope of the evaluation}

Provinces/territories and federal program representatives were consulted on an ongoing basis to determine the evaluation issues to examine. Each year, members of the multilateral Evaluation Steering Committee were consulted to identify their priority subject for the upcoming studies and voted on their preferred topics.

\section{Ongoing dissemination of evaluation findings}

Evaluation findings were shared with the provinces/territories and ESDC program stakeholders as they became available. At the end of the cycle, findings from each study were summarized in a bilateral report for each jurisdiction.

\section{Relying on administrative data as the main source of information for the evaluation}

The evaluation team capitalized on the fact that good quality administrative data about program beneficiaries were available at ESDC. The team created a longitudinal database for evaluation purposes. It included data from the Employment Insurance claims, program participation, ${ }^{3}$ and taxation files from the Canada Revenue Agency over a period of 20 years. It was updated annually with the most recent data available. It covered $100 \%$ of LMDA participants and up to $20 \%$ of EI claimants who never participated in the LMDAs. The latter data were used to 
create comparison groups for nonexperimental analyses of program incremental impacts. Overall, this database provided a wealth of historical information on participants' and nonparticipants' earnings, labour market attachment, and sociodemographic characteristics before and after participation.

Relying on administrative data to carry out the LMDA evaluation was possible because taxation data became accessible to ESDC evaluators toward the end of the first LMDA evaluation cycle. As well, over the years, the department has adopted strict rules and processes to maintain the privacy and security of the data. For example, data used for evaluation do not contain personal information such as Social Insurance Numbers, names, and addresses. Those are either removed from the file or masked with sequence numbers.

Under the new approach, administrative data were used to estimate program incremental impacts over up to five years after participation. Evaluators used propensity score matching techniques as in Blundell and Dias (2002), Gerfin and Lechner (2002), and Sianesi (2004) and estimated program impacts using difference-in-differences as in Heckman, Ichimura, and Todd (1997) and Heckman et al. (1999). For validation purposes, results were produced with three matching techniques (Kernel Matching, Inverse Probability Weighting, and Nearest Neighbours), and the models were tested with sensitivity analyses (e.g., rbound and mhbounds Stata command provided by DiPrete \& Gangl, 2004, and Becker \& Caliendo, 2007). Academic experts were hired to review the methodology and findings. Using propensity score matching techniques is common in evaluations of employment programs. They represent accessible alternatives to randomized control trials and were found to produce generally similar results as those from randomized control trials (Card, Kluve, \& Weber, 2015).

Administrative data were also used to produce various statistics on the sociodemographic profile of participants and their labour market outcomes over time. However, administrative data provide limited information on how the programs are designed, delivered, and targeted. Qualitative methods (e.g., key informant interviews) were used to examine those issues and explain the quantitative results.

\section{Conducting the Evaluations In-house}

All LMDA evaluation studies were conducted in-house by two teams. One team of three methodologists specialized in data processing and econometric analyses. This team was responsible for all questions related to data, methodologies, and quantitative analyses. Another team of three evaluators was responsible for the qualitative fieldwork, coordinating evaluation committees, maintaining relationships with partners, writing evaluation reports, and communicating findings.

\section{BENEFITS FROM THE NEW APPROACH}

Several benefits emerged from the new evaluation approach, including

Better supporting the policy development process. The scope of the evaluation was continuously adapted to better serve the needs of program managers and 
policy makers. Selecting the study subjects annually provided an opportunity to address the emerging evidence needs of evaluation users and to fill knowledge gaps identified in previous studies. Evaluation results were shared on an ongoing basis with key evaluation users through technical reports as well as regular presentations to the Performance Measurement and Evaluation Committee and to provinces/territories. Because of this flexibility and the ongoing sharing of information, evaluation results were used to support policy work on the future on the labour market transfers. As well, findings from the study on the impacts of early participation in Employment Assistance Services contributed to inform a new departmental initiative on early targeting of programs to unemployed individuals.

Regrouping efforts and sharing best practices. Working at the multilateral level gave an opportunity to provinces and territories to regroup efforts and exchange on best practices. In the first evaluations, quantitative analyses were often limited by the small number of participants in some of the smaller provinces/ territories. In the second cycle, when particular analyses were not possible, the province or territory was able attain insights from the national or regional level analyses (e.g., Atlantic). The national studies also highlighted best practices across Canada in terms of program design and delivery.

Producing highly credible and robust evidence on program incremental impacts. The quality and wealth of information in the administrative data coupled with the evaluation team capacity to apply state-of-the art econometric techniques generated robust estimates of program effects. With that regard, in 2014 the evaluation team invited ESDC officials to attend a panel of academic experts mandated to review methodologies and results. This panel confirmed the reliability of the impact estimates and helped evaluation users gain confidence in the value of the evaluation.

Demonstrating the value of collecting good data. At ESDC, evaluations of most labour market programs (e.g., programs targeted to youth or Employment Insurance benefits) rely on administrative data to examine impacts and/or outcomes. In fact, any programs that collect data on beneficiaries can potentially be evaluated using the same methods as those used for the LMDA evaluation. The LMDA evaluation provides another convincing example that investing in good quality data can lead to important payback. The use of administrative data produces robust evidence on program performance in a timely and efficient manner.

Reducing the cost of undertaking evaluation. Undertaking the work inhouse helped reducing evaluation costs. External contracts were limited to peer reviews and advice on methodology and data processing. These expenses approximated $\$ 70,000$ per year compared to about $\$ 1$ million per year for the first cycle.

\section{CONCLUSION}

At the time of writing this note, the second evaluation cycle was winding down and evaluators had had the opportunity to reflect on the lessons learned for the evaluation practice. 
Moving from a model where the evaluations are contracted to one where evaluations are undertaken in-house necessitated the development of internal capacity. It was crucial to build teams who had the technical skills to keep up with recent methodological developments and to implement innovative techniques. Building capacity required time and resources for research and training on methodologies.

Dividing the evaluation work across two specialized teams had some advantages since it allowed each team to develop expertise in its own area of work. The methodologists could focus on improving data processing and implementing innovative techniques, while the more generalist team could focus on ways to better communicate evaluation results. This division of work also had its challenges. It took some time for both teams to find an efficient way to coordinate and to communicate effectively about the expectations and constraints they are facing. For example, it is not because a certain type of analysis is feasible from a methodological standpoint that it is necessarily relevant from a policy standpoint.

Investing in the right tools, software, and computational capacity was also important. Having access to administrative data can allow quick analyses, but this work can only be done as quickly as technology allows, underscoring the vital importance of accessing appropriate technology.

As proposed by Michael Quinn Patton, evaluation that focuses on utilization should be designed for and with intended users (Patton, 2008). Directly involving all intended users of LMDA evaluation findings would have been nearly impossible, since LMDA programs are sometimes delivered by more than one department in the provinces/territories. Still, the success of this project in making evaluation more relevant to policy was largely due to having a governance process with clear roles and responsibilities and the ongoing consultation of evaluation committee members to ensure that all the players had an opportunity to express their interests. It was necessary to build in flexibility to allow committee members to conduct internal consultations on evaluation deliverables.

Toward the end of the cycle, provinces and territories as well as federal program representatives were surveyed to collect their views on the evaluation approach. They generally expressed a high level of satisfaction with the approach and its outcomes. The main concern noted was that the needs and interests of the small provinces/territories tend to get lost in the multilateral process.

Finally, having access to quality administrative data was critical, as it allowed the team to measure program incremental impacts and to do so in a timely and cost-effective manner. The LMDA evaluation was privileged in the sense that data on program participation and the labour market history before and after participation were available.

While this evaluation model cannot necessarily be replicated to other programs as is, some of its key features may be a source of inspiration for the evaluation of other federal/provincial/territorial agreements or horizontal initiatives. The third cycle of LMDA evaluation will build on the successes and lessons learned in this second cycle approach. 


\section{ACKNOWLEDGEMENTS}

In developing methodologies and analyses for LMDA evaluations, the evaluators benefited from advice and peer reviews from various academic experts. As well, in 2014, the evaluators held an internal expert panel to critically review and discuss the methodology for the incremental impact analysis. In particular, we would like to thank Professors Walter Nicholson, Jeff Smith, Guy Lacroix, and David Gray for providing advice on the LMDA evaluation studies.

\section{NOTES}

1 LMDA programs are offered only to Employment Insurance-eligible individuals with the exception of Employment Assistance Services, which are also provided to nonEmployment Insurance eligible individuals.

2 Agreements are available online at https://www.canada.ca/en/employment-socialdevelopment/programs/training-agreements/lmda.html

3 The agreements include data exchange provisions for the transfer of provincial/ territorial data on the participants and the programs in which they participated (see Labour Market Development Agreements, retrieved from https://www.canada.ca/en/ employment-social-development/programs/training-agreements/lmda.html).

\section{REFERENCES}

Becker, S.O., \& Caliendo, M. (2007). Sensitivity analysis for average treatment effects. Stata Journal, 7(1), 71-83. Retrieved from http://www.stata-journal.com/sjpdf. html?articlenum $=$ st 0121

Bloom, H. L., Orr, L. L., Bell, S. H., Cave, G., Doolittle, F., Lin, W., \& Bos, J. M. (1997). The benefits and costs of JTPA Title II-A programs. Key findings from the national Job Training Partnership Act Study. Journal of Human Resources, 32 (3), 549-576. Retrieved from http://faculty.georgetown.edu/cjh34/bloometal.pdf

Blundell, R., \& Dias, M.C. (2002). Alternative approaches to evaluation in empirical microeconomics. Portuguese Economic Journal, 1(2), 91-115. https://doi.org/10.1007/ s10258-002-0010-3

Bourgeois, I., \& Lahey, R. E. (2014). Case 6: Human Resources and Skills Development Canada. In I. Bourgeois \& B. Cousins (Eds.), Organisational capacity to do and use evaluation. New Directions for Evaluation, No. 141 (pp. 76-83). San Francisco, CA: Jossey-Bass.

Bourgeois, I., Toews, E., Whynot, J., \& Lamarche, M. K. (2013). Measuring organizational evaluation capacity in the Canadian federal government. Canadian Journal of Program Evaluation, 28(2), 1-19.

Canada. Parliament. House of Commons. Standing Committee on Human Resources, Skills and Social Development. (2015). Renewal of the Labour Market Development Agreements, 9th Report, 41st Parliament, Second Session. Retrieved from http://www. parl.gc.ca/HousePublications/Publication.aspx?DocId=6839662\&Language=E\&Mod $\mathrm{e}=1 \&$ Parl $=41 \&$ Ses $=2 \&$ File $=15$

Card, D., Kluve, J., \& Weber, A. (2015). What works? A meta-analysis of recent active labor market program evaluations (IZA Discussion Paper No. 9236). Retrieved from http:// ftp.iza.org/dp9236.pdf https://doi.org/10.3386/w21431. 
DiPrete, T. A., \& Gangl, M. (2004). Assessing bias in the estimation of causal effects: Rosenbaum bounds on matching estimators and instrumental variables estimation with imperfect instruments. Sociological Methodology, 34(1), 271-310. https://doi. org/10.1111/j.0081-1750.2004.00154.x

Gerfin, M., \& Lechner, M. (2002). A microeconometric evaluation of the active labour market policy in Switzerland. Economic Journal (London), 112(482), 854-893. https:// doi.org/10.1111/1468-0297.00072

Government of Canada, Treasury Board Secretariat. (2009). Policy on Evaluation. Retrieved from https://www.tbs-sct.gc.ca/pol/doc-eng.aspx?id=31300

Gunderson, M. (2003). Active labour market adjustment policies: What we know and don't know (Report prepared for the Role of Government Panel). Retrieved from http:// www.ontla.on.ca/library/repository/mon/8000/244125.pdf

Heckman, J. J., Ichimura, H., \& Todd, P. (1997). Matching as an econometric evaluation estimator: Evidence from evaluating a job training program. Review of Economic Studies, 64(4), 605-654. https://doi.org/10.2307/2971733

Heckman, J., Lalonde, R., \& Smith, J. (1999). The economics and econometrics of active labor market programs. In O. Ashenfelter \& D. Card (Eds.), Handbook of labor economics (Vol. 3, pp. 1865-2097). North Holland: Elsevier Science. https://doi.org/10.1016/ S1573-4463(99)03012-6

Heckman, J., Moon, S. H., Pinto, R., Savelyev, P. A., \& Yavitz, A. (2010). The rate of the return to the High Scope Perry Preschool Program. Journal of Public Economics, 94(12), 114-128. Retrieved from http://jenni.uchicago.edu/papers/Heckman_Moon_ etal_2010_JPubEc_v94_n1.pdf https://doi.org/10.1016/j.jpubeco.2009.11.001

Patton, M. Q. (2008). Utilization-focused evaluation. Thousand Oaks, CA: Sage.

Sianesi, B. (2004). An Evaluation of the Swedish System of Active Labour Market Programs in the 1990s. Review of Economics and Statistics, 86(1), 133-155. https:// doi.org/10.1162/003465304323023723

\section{AUTHOR INFORMATION}

Yves Gingras has been the Director General of the Evaluation Directorate at Employment and Social Development Canada since 2013. He studied economics at Laval University, and earned his MA in 1992 with a fellowship from Natural Resources Canada. Prior to this, he studied at the Royal Military College of Saint-Jean. In 1992 he joined the Public Service of Canada through the Accelerated Training Program for Economists. Subsequently, he worked as a researcher at HRDC and as a policy advisor at the Priorities and Planning Secretariat at the Privy Council Office. In 2004 he joined Finance Canada as a chief in the Personal Income Tax Division. He was appointed Senior Director in 2009 and interim DG of the Labour Market Policy Directorate at HRDC in 2010. He represented Canada at the Employment, Labour and Social Affairs Committee of the OECD. He also did research at Laval University, the Central Bank of Finland, and the Central Bank of Malta. He has published articles on energy and labour market issues.

Tony Haddad completed his PhD in sociology at York University in 1998. He was the Director of the Partnership Evaluation Division from 2006 to 2014, during which he led the evaluation work on labour market programs funded by ESDC and delivered by provinces, 
territories, and organizations, including Indigenous communities. Under his lead, the Partnership Evaluation Division developed and refined the use of linked program administrative data to undertake evaluation work that was more timely, less resources intensive, and very statistically robust. He is currently leading the Indigenous Labour Market Information team within the Indigenous Affairs Directorate, Skills and Employment Branch, in ESDC.

Andy Handouyahia has been working in data science for more than 25 years. He is currently a manager in the Evaluation Directorate at Employment and Social Development Canada where he is responsible for data and methodology. He earned an MA in science in 1997 from Université de Sherbrooke. He has been giving lectures at Université du Québec en Outaouais for approximately 20 years. He has been responsible for data collection and management at Statistics Canada for more than 13 years and has also worked at the Treasury Board Secretariat of Canada as a manager of business solutions.

Georges Awad has an MA in economics from the Université de Montréal. After working two years as an economist in Emploi-Québec, he joined the Evaluation Directorate of Employment and Social Development Canada in April 2001. He continues to occupy the position of an evaluation manager since 2005 , working on the evaluation of various labour market programs.

Stéphanie Roberge is a senior program evaluator. She started working in evaluation at Canadian Heritage in 2006. She joined Employment and Social Development Canada few months later and has been working in the Evaluation Directorate since then. She earned an MA in political science with a specialization in public policy and public administration from Université de Montréal in 2005. 